\title{
Eco-Friendly Production of Silver Nanoparticles from Peel of Tangerine for Degradation of Dye
}

\author{
Eman Alzahrani \\ Chemistry Department, Faculty of Science, Deanship of Scientific Research, Taif University, Taif, KSA \\ Email: em-s-z@hotmail.com
}

Received 21 January 2015; accepted 6 February 2015; published 11 February 2015

Copyright (c) 2015 by author and Scientific Research Publishing Inc.

This work is licensed under the Creative Commons Attribution International License (CC BY).

http://creativecommons.org/licenses/by/4.0/

(c) () Open Access

\section{Abstract}

Green chemistry methods for production of nanoparticles have many advantages, such as ease of use, which makes the methods desirable and economically viable. The aim of the present work was to green synthesise silver nanoparticles (SNPs) using aqueous tangerine peel extract in different ratios (2:1, 1:1, 1:2). The formed SNPs were characterised using ultraviolet-visible (UV-Vis) spectrophotometry, and transmission electron microscopy (TEM). The UV-Vis spectra showed that the highest absorbance was observed when the ratio of peel tangerine extract to silver nitrate solution was 1:2. The transmission electron micrographs showed the formation of poly dispersed nanoparticles. It was found that the average diameter of the nanoparticles was $30.29 \pm 5.1 \mathbf{~ n m}$, $16.68 \pm 5.7 \mathrm{~nm}$, and $25.85 \pm 8.4 \mathrm{~nm}$, using a tangerine peel solution and silver nitrate solution ratio of 2:1, 1:1, and 1:2, respectively. The formed SNPs were evaluated as catalysts for methyl orange dye degradation, and the results confirmed that SNPs can speed up the degradation of the dye.

\section{Keywords}

Green Process, Synthesis Silver Nanoparticle, Tangerine Peel Extract, Degradation of Dye, Methyl Orange

\section{Introduction}

Nanomaterials have been receiving attention due to their unique physical and chemical properties compared with 
their larger-size counterparts [1]-[3]. An example of nanostructured materials are silver nanoparticles (SNPs), and they have been utilised in different fields such as physics, chemistry, biology, and medicine. Recently, silver nanoparticles have been found to exhibit interesting antibacterial activities, burn treatments, coating stainless steel metals, and sun creams [4]-[7].

The noble metal nanoparticles have been fabricated by chemical reduction with stabilising reagents $\left(\mathrm{NaBH}_{4}\right.$, citrate, or ascorbate) [8], thermal decomposition [9], photo reduction in reverse micelles [10], and radiation chemical reduction [11]. Many of these approaches are expensive, consume a lot of energy, result in low yields, and the chemicals used in their production are toxic and hazardous [12].

Recently, silver nanoparticles have been formed by biological approaches, such as using microorganisms [13], enzymes [14], and fungus [15]. The disadvantages of these approaches are they need special culture preparation and isolation techniques for synthesis of the nanoparticles [16] [17]. Silver nanoparticles have also been fabricated using plant extracts as reducing and capping agents. The main advantages of using plant extracts are that the process is simple, cheap, scaling-up, eco-friendly, and safe [18]-[21].

Shankar et al. [22] fabricated silver nanoparticles using neem leaf; however, the required time for a $90 \%$ reduction was about 4 hours. In this work, a simple and fast chemical reaction for the fabrication of silver nanoparticles using tangerine peel extract as a reducing and stabilising agent was investigated. To the best of our knowledge, this is the first paper examining the use of tangerine peel extract for large-scale production of SNPs. The fabricated nanoparticles were characterised using UV-Visible absorption spectroscopy, and transmission electron microscopy. In this paper, using SNPs as a catalyst for degradation of dye was studied. The chosen dye was methyl orange dye (MO) which is an anionic azo dye.

\section{Experimental}

\subsection{Chemicals and Materials}

Tangerine peel was collected from a local shop (Taif, KSA). Silver nitrate $\left(\mathrm{AgNO}_{3}\right)(99.8 \%)$ was purchased from Sigma-Aldrich (Poole, UK). The Whatman filter paper (pore size $25 \mu \mathrm{m}$ and diam. $15 \mathrm{~cm}$ ) was purchased from Sigma-Aldrich (Poole, UK). Distilled water was employed for preparing all the solutions and reagents. Methyl orange, sodium borohydride $\left(\mathrm{NaBH}_{4}\right)$ and hydrogen peroxide $\left(\mathrm{H}_{2} \mathrm{O}_{2}\right)$ were purchased from Fisher Scientific (Loughborough, UK).

\subsection{Instrumentation}

Transmission electron microscopy (TEM) from JEOL Ltd. (Welwyn Garden City, UK), a water bath from Poly Science (Niles, Illinois, US), a UV-Vis spectrophotometer from Thermo Scientific ${ }^{\mathrm{TM}}$ GENESYS 10S (Toronto, Canada).

\subsection{Synthesis of Silver Nanoparticles (SNPs)}

$20 \mathrm{~g}$ of tangerine peel was added to $100 \mathrm{~mL}$ deionised water. The mixture was boiled at $80^{\circ} \mathrm{C}$ for $5 \mathrm{~min}$. The solution was filtered using Whatman paper then added to silver nitrate solution $(2 \mathrm{mM})$ indifferent ratios $(2: 1,1: 1$, $1: 2)$ at room temperature $\left(25^{\circ} \mathrm{C} \pm 3^{\circ} \mathrm{C}\right)$ without stirring. Reduction of silver ions into silver nanoparticles commonly followed by colour change and the formation of SNPs can be visually observed [3]. Therefore, the change of colour was visually monitored to check for the formation of SNPs. The fabricated silver nanoparticles solutions were stored at $2^{\circ} \mathrm{C}$ and were utilised within one week.

\subsection{Characterisation of the Synthesised Silver Nanoparticles}

\subsubsection{UV-Vis Spectroscopy}

The prepared silver nanoparticle solutions were observed by ultraviolet-visible spectrophotometer. The bioreduction of the $\mathrm{Ag}^{+}$ions in solution was checked by periodic sampling of aqueous component and observing the UV-Vis spectrum at different time intervals. $100 \mu \mathrm{L}$ of solution was diluted with $1 \mathrm{~mL}$ deionised water then the absorbance of the mixture was measured using a UV-Vis spectrophotometer and compared with $1 \mathrm{~mL}$ of distilled water as a blank over the range $350-800 \mathrm{~nm}$ operated at resolution of 1 $\mathrm{nm}$. 


\subsubsection{TEM Analysis}

The formation of SNPs was confirmed by using transmission electron microscopy (TEM). In addition, the size and the morphology of the SNPs were characterised by TEM. For this, $5 \mu \mathrm{L}$ of the sample solution was put onto lacy carbon-coated $3 \mathrm{~mm}$ diameter copper grids. TEM images were acquired with a Gatan Ultrascan 4000 digital camera attached to a JEOL 2010 transmission electron microscope running at $20 \mathrm{kV}$. The size of the prepared SNPs was measured using image J software.

\subsection{Catalytic Reduction of Dye Using SNPs}

Using SNPs as a catalyst in dyedegradation was checked using methyl orange dye. This was performed by mixing $1 \mathrm{~mL}$ of methyl orange solution $\left(3 \times 10^{-4} \mathrm{M}\right)$ with $1.5 \mathrm{~mL}$ distilled water, $1 \mathrm{~mL}$ of $\mathrm{H}_{2} \mathrm{O}_{2}$ solution $(0.001 \mathrm{M})$ or $1 \mathrm{~mL}$ of $\mathrm{NaBH}_{4}(0.001 \mathrm{M})$ solution, and $500 \mu \mathrm{L}$ of SNPs. The progress of the reaction was monitored using UV-Vis spectrophotometer at a wavelength of $465 \mathrm{~nm}$. For the uncatalysed reaction, $500 \mu \mathrm{L}$ of SNPs was replaced by an equal amount of distilled water.

\section{Results and Discussion}

\subsection{Visual Observation Study}

The present study deals with the biosynthesis of silver nanoparticles (SNPs) using tangerine peel. The main advantages of using green processes are rapidity, low cost, low environmental impact, and a single-step procedure for biofabrication [12] [23]. In this study, different ratios of silver nitrate solution and aqueous extract of tangerine peel (2:1, 1:1, and 1:2) were utilised without any stirring and hence the use of energy was minimal. It is known that the reduction of silver ion $\left(\mathrm{Ag}^{+}\right)$into silver $(\mathrm{Ag})$ nanoparticles during exposure to the plant extracts commonly followed by colour change and the formation of SNPs was visually observed [3]; therefore, the colour of the mixtures were observed.

Figure 1 shows the colour change of the solutions, which were silver nitrate solution (1) and tangerine peel solution (2), to dark brown after synthesis of silver nanoparticles using different ratios of silver nitrate solution to tangerine peel solution, (3) 2:1, (4) 1:1, and (5) 1:2, at different times: 15 min (Figure 1(a)), 30 min (Figure 1(b)), and after 45 min (Figure 1(c)). It was observed that the colour of the mixture changed immediately after mixing the silver nitrate solution with the extract solution, which confirmed that aqueous silver ions can be reduced by aqueous extract of tangerine peel to form stable SNPs in water. The reason for the brown colour is due to the excitation of surface plasmon vibrations in the silver metal nanoparticles [3] [24].

\subsection{UV-Visible Spectral Analysis of SNPs}

It is known that the UV-Vis spectrophotometer can be utilised for checking the formation of metal nanoparticles in aqueous suspensions [25]. Therefore, the progress of silver nanoparticle formation was monitored spectrophotometrically as a function of time of reaction over the range $350-800 \mathrm{~nm}$, and the peak wavelength $\left(\lambda_{\max }\right)$

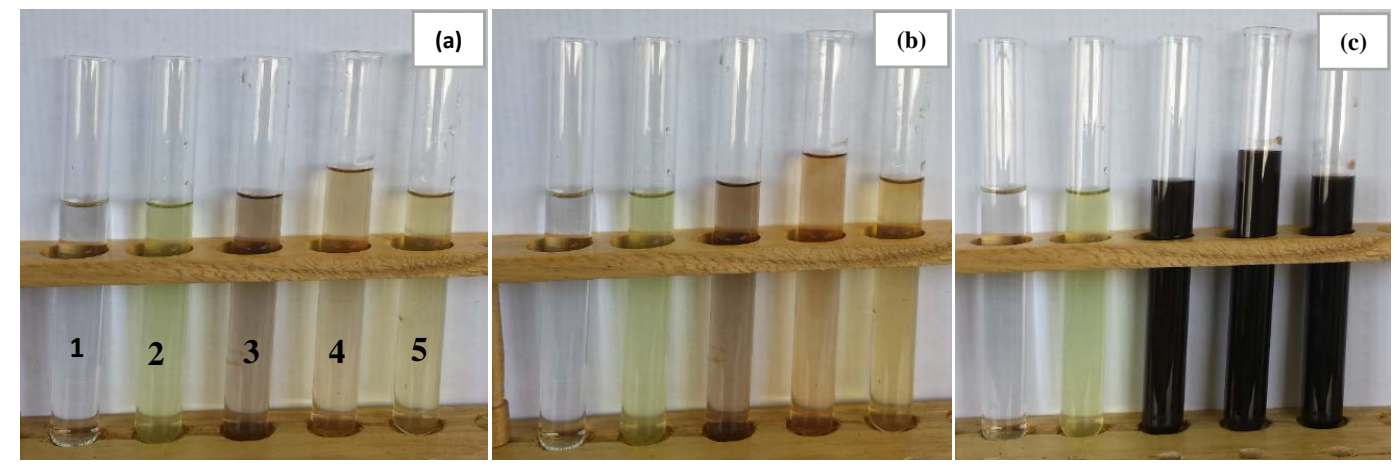

Figure 1. Photographs showing colour changes of silver nitrate solution (2 mM) after adding of extract of tangerine peel solution after reaction time: (a) $15 \mathrm{~min}$; (b) $30 \mathrm{~min}$; (c) $45 \mathrm{~min}$. (1) silver nitrate solution (2) extraction of tangerine peel solution, (3) ratio of silver nitrate solution to tangerine peel solution 2:1, (4) 1:1, and (5) $1: 2$. 
and value of the absorbance (O.D.) were recorded. Table 1 presents the wavelength of maximum absorption $\left(\lambda_{\max }\right)$ and value of the absorbance (O.D.) of the reaction medium at different times (15 min, $30 \mathrm{~min}$, and $45 \mathrm{~min}$ ). It was noted that absorbance increased with time, from 15 min to 45 min. Formation of SNPs happened within 45 min of reaction, making this study one of the fastest green processes to produce SNPs, compared with a previous work [26] which took approximately $2 \mathrm{~h}$. After $45 \mathrm{~min}$, there was no increase in the absorbance due to the depletion of the silver ions (the initial material).

The ratio of silver nitrate solution to tangerine peel extraction in the reaction mixture was investigated, as can be seen in Table 1. It was found that the highest absorbance was obtained when the ratio of peel tangerine extract to silver nitrate solution was 1:2, and the absorbance was in the range $0.416-1.181$. This confirmed that the yield of the formed SNPs can be affected by metal-extract proportions, as was noted in a previous study [27]. In addition, it was found that the maximum absorption peaks were between 419 to $435 \mathrm{~nm}$. It was observed throughout the reaction period that fabricated SNPs were dispersed in the aqueous solution and stable for more than 6 months, with little sign of aggregation.

\subsection{TEM Study}

The fabricated SNPs were characterised using TEM analysis. Figure 2 shows the TEM electron microscopy micrographs showing the formation of nanoparticles. The TEM micrographs showed that all the fabricated SNPs using different ratios of silver nitrate solution and tangerine peel extract were spherical in shape and they were dispersed in aqueous medium.

It was found that the size of the formed SNPs depends on the ratio of extract tangerine peel to silver nitrate solution. The size of SNPs was $30.29 \pm 5.1$ when the ratio of extract tangerine peel to silver nitrate solution was $2: 1$ while if the ratio solution was 1:1, the size of nanoparticles was $16.68 \pm 5.7$. Moreover, it was found that the size of the prepared SNPs using silver nitrate solution and tangerine peel solution (2:1) was $25.85 \pm 8.4$.

\subsection{Effect of Silver Nanoparticles in Catalysing Degradation of Methyl Orange}

The rate of degradation of MO. dye by sodium borohydride $\left(\mathrm{NaBH}_{4}\right)$ or hydrogen peroxide $\left(\mathrm{H}_{2} \mathrm{O}_{2}\right)$ was monitored $(0-60 \mathrm{~min})$ in the absence and presence of silver nanoparticles that were prepared using the ratio of extract of tangerine peel to silver nitrate solution 1:2 (The ratio that gave the highest absorbance). The effect of silver nanoparticles in catalysing degradation of the dye was monitored spectrophotometrically, as can be seen in Figure 3. It was found that the absorbance of the dye decreased rapidly when using SNPs compared to without using SNPs. These results confirmed that SNPs can be used to catalyse the degradation of organic pollutants.

Table 1. Absorption maxima $(\lambda)$ and absorbance SNPs prepared from tangerine peel, showing effect of reaction time, and silver nitrate solution: Peel tangerine extract ratio.

\begin{tabular}{|c|c|c|c|c|c|c|c|}
\hline \multirow{3}{*}{ Sample } & \multirow{3}{*}{$\begin{array}{l}\text { Time } \\
\text { (min) }\end{array}$} & \multicolumn{6}{|c|}{ Ratio of peel tangerine extract to silver nitrate solution } \\
\hline & & \multicolumn{2}{|r|}{$2: 1$} & \multicolumn{2}{|c|}{$1: 1$} & \multicolumn{2}{|c|}{$1: 2$} \\
\hline & & $\lambda_{\max }$ & Absorbance & $\lambda_{\max }$ & Absorbance & $\lambda_{\max }$ & Absorbance \\
\hline \multirow{4}{*}{1} & 0 & - & - & - & - & - & - \\
\hline & 15 & 428 & 0.255 & 431 & 0.341 & 428 & 0.451 \\
\hline & 30 & 435 & 0.514 & 428 & 0.677 & 419 & 0.919 \\
\hline & 45 & 435 & 0.692 & 431 & 0.754 & 435 & 1.088 \\
\hline \multirow{4}{*}{2} & 0 & - & - & - & - & - & - \\
\hline & 15 & 425 & 0.242 & 419 & 0.396 & 419 & 0.416 \\
\hline & 30 & 433 & 0.479 & 431 & 0.690 & 430 & 0.949 \\
\hline & 45 & 431 & 0.676 & 431 & 0.811 & 433 & 1.086 \\
\hline \multirow{4}{*}{3} & 0 & - & - & - & - & - & - \\
\hline & 15 & 422 & 0.273 & 431 & 0.416 & 431 & 0.436 \\
\hline & 30 & 419 & 0.582 & 428 & 0.705 & 425 & 1.060 \\
\hline & 45 & 435 & 0.715 & 419 & 0.819 & 422 & 1.181 \\
\hline
\end{tabular}



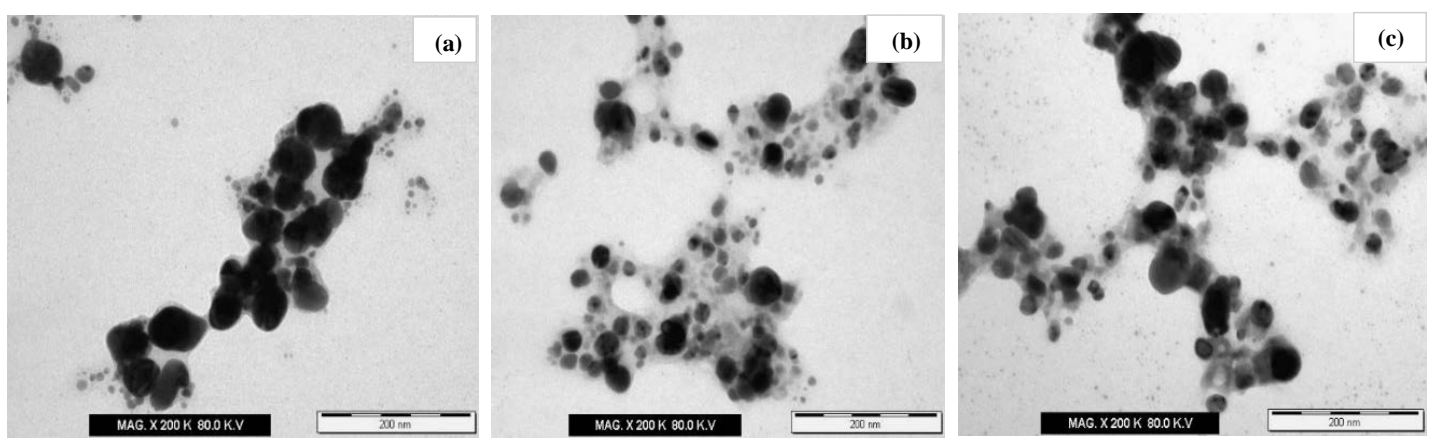

Figure 2. TEM images of the fabricated SNPs using different ratio of extract of tangerine peel solution to silver nitrate solution: (a) 20:10; (b) 10:10; (c) 10:20.
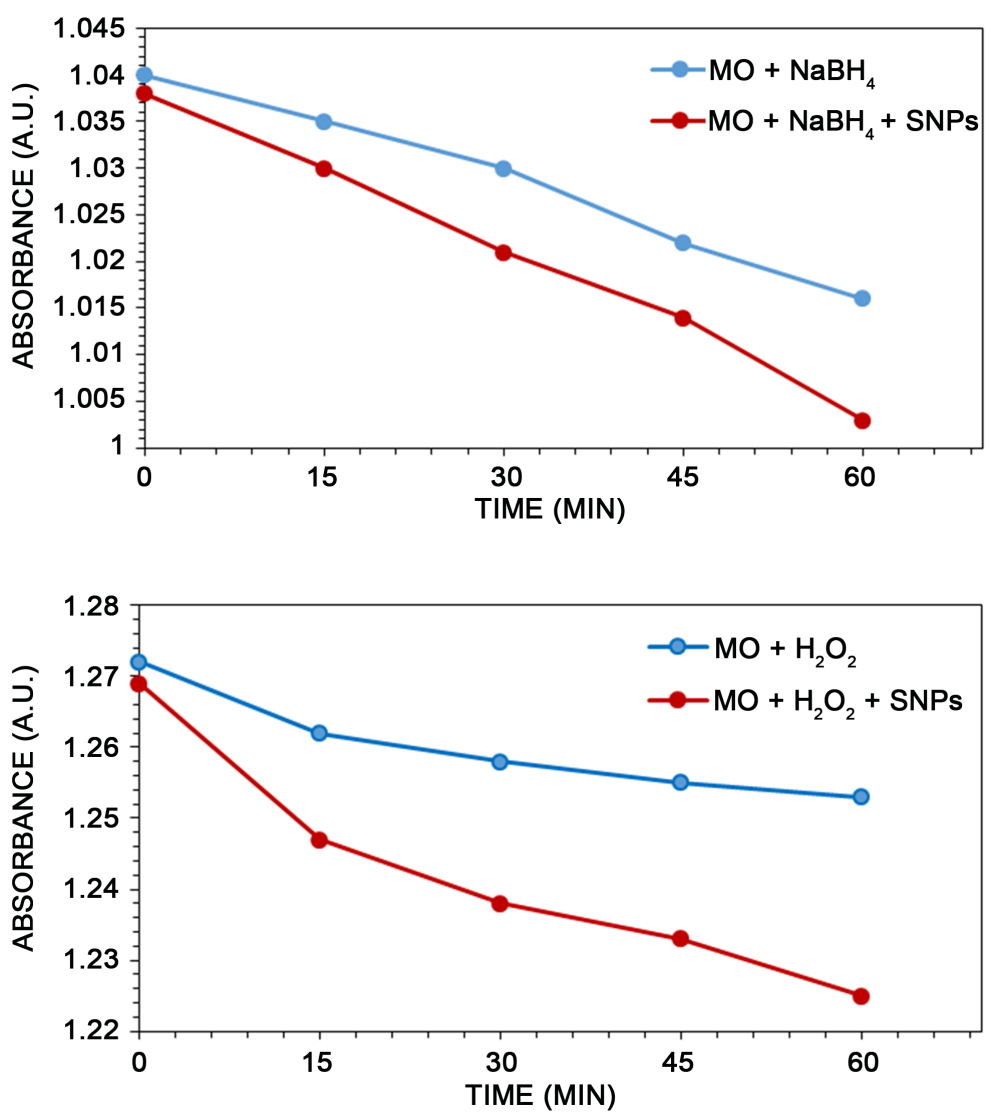

Figure 3. Degradation of the methyl orange solution $\left(3 \times 10^{-4} \mathrm{M}\right)$ in the absence and presence of SNPs $(500 \mu \mathrm{L})$ and $1 \mathrm{~mL}$ of $\mathrm{NaBH}_{4}$ solution $(0.001 \mathrm{M})$ or $\mathrm{H}_{2} \mathrm{O}_{2}$ solution $(0.001 \mathrm{M})$.

\section{Conclusion}

The bioreduction of aqueous silver ions by the tangerine peel extract was demonstrated in the present study. It was found that this procedure is very simple, fast, eco-friendly, and can form quite stable SNPs in solution, confirming that tangerine peel can be a good source for preparation of silver nanoparticles, and is an alternative method for synthesis of metal nanoparticles. In addition, it was found that the ratio of tangerine peel extract solution to silver nitrate solution can affect the sizes and the yields of SNPs. Moreover, this study showed that SNPs can be utilised to catalyse degradation of dye. It would be interesting to utilise the fabricated SNPs for degradation of organic pollutants. 


\section{References}

[1] Fayaz, A.M., et al. (2010) Biogenic Synthesis of Silver Nanoparticles and Their Synergistic Effect with Antibiotics: A Study against Gram-Positive and Gram-Negative Bacteria. Nanomedicine: Nanotechnology, Biology and Medicine, 6, 103-109. http://dx.doi.org/10.1016/j.nano.2009.04.006

[2] Vijayakumar, M., et al. (2013) Biosynthesis, Characterisation and Anti-Bacterial Effect of Plant-Mediated Silver Nanoparticles Using Artemisia nilagirica. Industrial Crops and Products, 41, 235-240. http://dx.doi.org/10.1016/j.indcrop.2012.04.017

[3] Alzahrani, E. and Welham, K. (2014) Optimization Preparation of the Biosynthesis of Silver Nanoparticles Using Watermelon and Study of Its Antibacterial Activity. International Journal of Basic and Applied Sciences, 3, 392-400. http://dx.doi.org/10.14419/ijbas.v3i4.3358

[4] Song, J.Y. and Kim, B.S. (2009) Rapid Biological Synthesis of Silver Nanoparticles Using Plant Leaf Extracts. Bioprocess and Biosystems Engineering, 32, 79-84. http://dx.doi.org/10.1007/s00449-008-0224-6

[5] Rai, M., Yadav, A. and Gade, A. (2009) Silver Nanoparticles as a New Generation of Antimicrobials. Biotechnology Advances, 27, 76-83. http://dx.doi.org/10.1016/j.biotechadv.2008.09.002

[6] Kumar, A., et al. (2008) Silver-Nanoparticle-Embedded Antimicrobial Paints Based on Vegetable Oil. Nature Materials, 7, 236-241. http://dx.doi.org/10.1038/nmat2099

[7] Furno, F., et al. (2004) Silver Nanoparticles and Polymeric Medical Devices: A New Approach to Prevention of Infection. Journal of Antimicrobial Chemotherapy, 54, 1019-1024. http://dx.doi.org/10.1093/jac/dkh478

[8] Liz-Marzán, L.M. and Lado-Tourino, I. (1996) Reduction and Stabilization of Silver Nanoparticles in Ethanol by Nonionic Surfactants. Langmuir, 12, 3585-3589. http://dx.doi.org/10.1021/la951501e

[9] Esumi, K., et al. (1990) Preparation and Characterization of Bimetallic Palladium-Copper Colloids by Thermal Decomposition of Their Acetate Compounds in Organic Solvents. Chemistry of Materials, 2, 564-567. http://dx.doi.org/10.1021/cm00011a019

[10] Sun, Y., Atorngitjawat, P. and Meziani, M.J. (2001) Preparation of Silver Nanoparticles via Rapid Expansion of Water in Carbon Dioxide Microemulsion into Reductant Solution. Langmuir, 17, 5707-5710. http://dx.doi.org/10.1021/la0103057

[11] Henglein, A. (1993) Physicochemical Properties of Small Metal Particles in Solution: "Microelectrode” Reactions, Chemisorption, Composite Metal Particles, and the Atom-to-Metal Transition. The Journal of Physical Chemistry, 97, 5457-5471. http://dx.doi.org/10.1021/j100123a004

[12] Ponarulselvam, S., Panneerselvam, C., Murugan, K., Aarthi, N., Kalimuthu, K. and Thangamani, S. (2012) Synthesis of Silver Nanoparticles Using Leaves of Catharanthus roseus Linn. G. Don and Their Antiplasmodial Activities. Asian Pacific Journal of Tropical Biomedicine, 2, 574-580. http://dx.doi.org/10.1016/S2221-1691(12)60100-2

[13] Konishi, Y., Ohno, K., Saitoh, N., Nomura, T., Nagamine, S., Hishida, H., et al. (2007) Bioreductive Deposition of Platinum Nanoparticles on the Bacterium Shewanella algae. Journal of Biotechnology, 128, 648-653. http://dx.doi.org/10.1016/j.jbiotec.2006.11.014

[14] Willner, I., Baron, R. and Willner, B. (2006) Growing Metal Nanoparticles by Enzymes. Advanced Materials, 18, 11091120. http://dx.doi.org/10.1002/adma.200501865

[15] Zhang, X.R., He, X.X., Wang, K.M. and Yang, X.H. (2011) Different Active Biomolecules Involved in Biosynthesis of Gold Nanoparticles by Three Fungus Species. Journal of Biomedical Nanotechnology, 7, 245-254. http://dx.doi.org/10.1166/jbn.2011.1285

[16] Saxena, A., Tripathi, R. and Singh, R. (2010) Biological Synthesis of Silver Nanoparticles by Using Onion (Allium сера) Extract and Their Antibacterial Activity. Digest Journal of Nanomaterials and Biostructures, 5, 427-432.

[17] Jain, D., Daima, H.K., Kachhwala, S. and Kothari, S.L. (2009) Synthesis of Plant-Mediated Silver Nanoparticles Using Papaya Fruit Extract and Evaluation of Their Anti Microbial Activities. Digest Journal of Nanomaterials and Biostructures, 4, 557-563.

[18] Azar, A.R.J. and Mohebbi, S. (2013) One-Pot Greener Synthesis of Silver Nanoparticles Using Tangerine Peel Extract: Large-Scale Production. Micro \& Nano Letters, 8, 813-815. http://dx.doi.org/10.1049/mnl.2013.0473

[19] Moulton, M.C., Braydich-Stolle, L.K., Nadagouda, M.N., Kunzelman, S., Hussain, S.M. and Varma, R.S. (2010) Synthesis, Characterization and Biocompatibility of "Green” Synthesized Silver Nanoparticles Using Tea Polyphenols. Nanoscale, 2, 763-770. http://dx.doi.org/10.1039/c0nr00046a

[20] Dubey, M., Bhadauria, S. and Kushwah, B. (2009) Green Synthesis of Nanosilver Particles from Extract of Eucalyptus hybrida (Safeda) Leaf. Digest Journal of Nanomaterials and Biostructures, 4, 537-543.

[21] Parashar, V., Parashar, R., Sharma, B. and Pandey, A.C. (2009) Parthenium Leaf Extract Mediated Synthesis of Silver Nanoparticles: A Novel Approach towards Weed Utilization. Digest Journal of Nanomaterials and Biostructures, 4, 
45-50.

[22] Shankar, S.S., Rai, A., Ahmad, A. and Sastry, M. (2004) Rapid Synthesis of Au, Ag, and Bimetallic Au Core-Ag Shell Nanoparticles Using Neem (Azadirachta indica) Leaf Broth. Journal of Colloid and Interface Science, 275, 496-502. http://dx.doi.org/10.1016/j.jcis.2004.03.003

[23] Mittal, A.K., Chisti, Y. and Banerjee, U.C. (2013) Synthesis of Metallic Nanoparticles Using Plant Extracts. Biotechnology Advances, 31, 346-356. http://dx.doi.org/10.1016/j.biotechadv.2013.01.003

[24] Xu, H. and Käll, M. (2002) Surface-Plasmon-Enhanced Optical Forces in Silver Nanoaggregates. Physical Review Letters, 89, Article ID: 246802. http://dx.doi.org/10.1103/PhysRevLett.89.246802

[25] (2011) Biofabrication of Ag Nanoparticles Using Moringa oleifera Leaf Extract and Their Antimicrobial Activity. Asian Pacific Journal of Tropical Biomedicine, 1, 439-442. http://www.ncbi.nlm.nih.gov/pmc/articles/PMC3614222/pdf/apjtb-01-06-439.pdf

[26] Kim, J.S., Kuk, E., Yu, K.N., Kim, J.-H., Park, S.J., Lee, H.J., et al. (2007) Antimicrobial Effects of Silver Nanoparticles. Nanomedicine: Nanotechnology, Biology and Medicine, 3, 95-101. http://dx.doi.org/10.1016/j.nano.2006.12.001

[27] Ganaie, S.U., Abbasi, T., Anuradha, J. and Abbasi, S.A. (2014) Biomimetic Synthesis of Silver Nanoparticles Using the Amphibious Weed Ipomoea and Their Application in Pollution Control. Journal of King Saud University-Science, 26, 222-229. http://dx.doi.org/10.1016/j.jksus.2014.02.004 
Scientific Research Publishing (SCIRP) is one of the largest Open Access journal publishers. It is currently publishing more than 200 open access, online, peer-reviewed journals covering a wide range of academic disciplines. SCIRP serves the worldwide academic communities and contributes to the progress and application of science with its publication.

Other selected journals from SCIRP are listed as below. Submit your manuscript to us via either submit@scirp.org or Online Submission Portal.
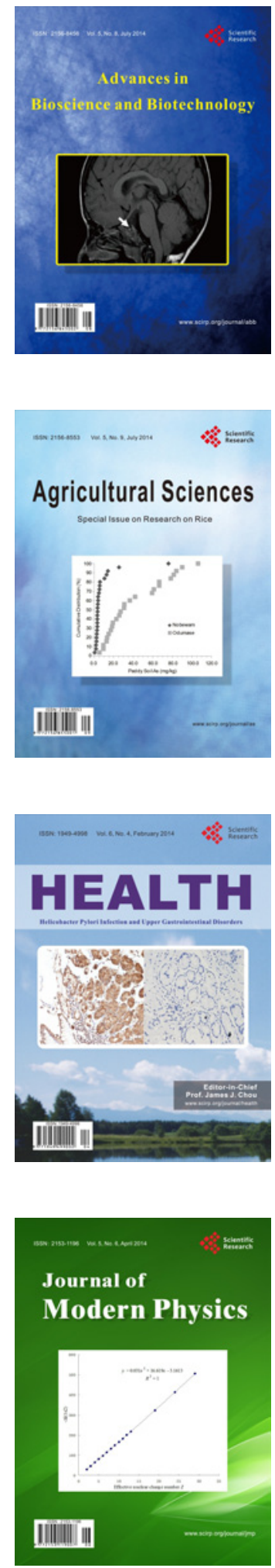
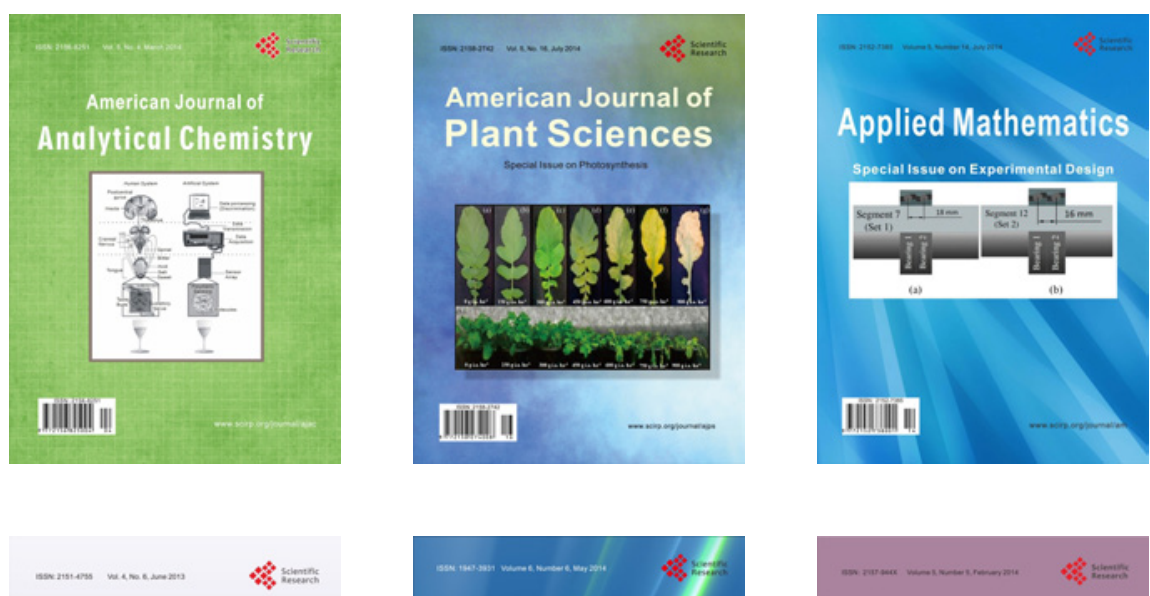

Creative Education
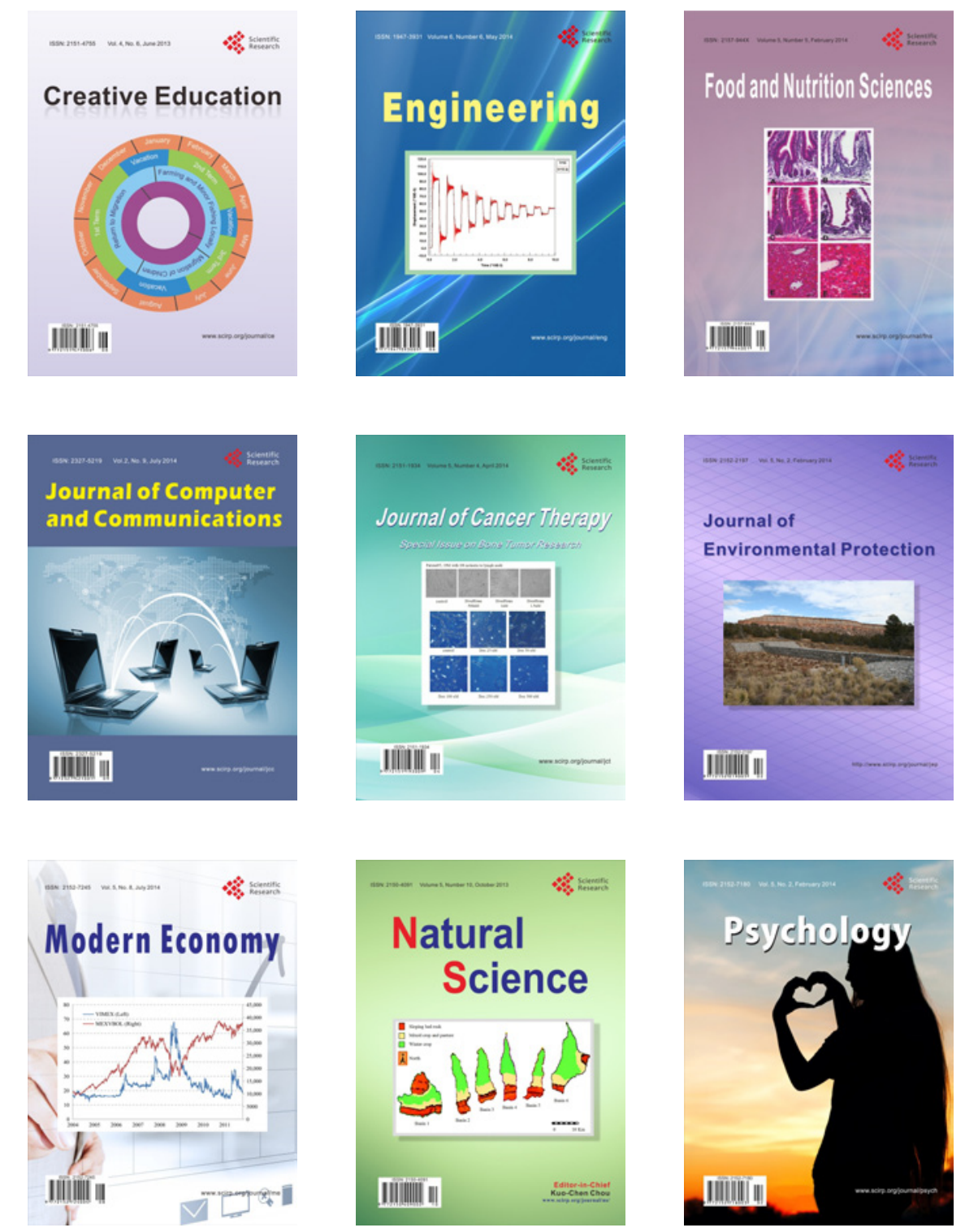